\title{
Polifonia retrofuturista: a (re)criação de vozes literárias na série Brasiliana Steampunk
}

\author{
Retrofuturist polyphony: the (re)creation of literary voices \\ in Braziliana Steampunk series
}

\author{
ENÉIAS FARIAS TAVARES* \\ Universidade Federal de Santa Maria, Santa Maria, RS, Brasil
}

\begin{abstract}
Resumo: Neste ensaio, apresentarei o processo de criação da série Brasiliana Steampunk através de três fenômenos culturais: a apropriação de obras em domínio público, a justaposição de diferentes personagens em um único universo e a utilização da estética steampunk. Num segundo momento, discutirei como procedi na recriação dos heróis clássicos da literatura brasileira. Por fim, mostrarei como esse trabalho de adaptação de vozes literárias preexistentes me levou ao desenvolvimento de três personagens inéditos do romance $A$ lição de anatomia do temível dr. Louison: o investigador Pedro Britto Cândido, a escritora feminista Beatriz de Almeida \& Souza e o médico e esteta Antoine Louison.
\end{abstract}

Palavras-chave: processo criativo; escrita criativa; literatura steampunk; ficção científica.

\begin{abstract}
In this essay, I will present the creation of Brasiliana Steampunk series through three cultural phenomena: the appropriation of literary works in public domain, the juxtaposition of different characters in a single universe and the use of steampunk aesthetics. In a second moment, I will discuss how I proceeded in the recreation of the classic heroes of Brazilian literature. Finally, I will show how this work of adapting preexisting literary voices led me to the development of three new characters of the novel $A$ lição de anatomia do temível dr. Louison: researcher Pedro Britto Cândido, feminist writer Beatriz de Almeida \& Souza, and physician and esthete Antoine Louison.
\end{abstract}

Keywords: creative process; creative writing; steampunk literature; science fiction.

\footnotetext{
* Mestre e Doutor em Estudos Literários. Professor de Literatura Clássica do Departamento de Letras Clássicas e Linguística da Universidade Federal de Santa Maria. Pesquisador do Laboratório CORPUS e Professor Credenciado do Programa de Pós-Graduação em Letras da UFSM, onde orienta trabalhos sobre os Livros Iluminados de William Blake, literatura fantástica e o insólito literário no século XIX e XX.
} 


\section{Introdução: ideias criativas \& vozes narrativas}

Para um escritor, a pergunta fulcral no início de todo projeto ficcional é: quem contará a história? A esta pergunta, se apresentam as opções mais comuns - narrador(a) em primeira ou em terceira pessoa -, que posteriormente darão lugar a diversas subdivisões que comunicarão uma observação neutra, engajada, subjetiva, onisciente ou focalizada, entre outras. A resposta a respeito de quem irá narrar repercute em uma série de escolhas posteriores, que afetarão a observação e a proximidade do leitor em relação ao narrado, que emitirá ou não comentários opinativos, que participará ou não dos dramas e dos conflitos apresentados, aproximando ou afastando o leitor ou a leitora da experiência narrativa.

A predileção do romance contemporâneo por um narrador pretensamente neutro - como uma câmera cinematográfica - ou construído através do fluxo de consciência - no qual o narrado é pouco confiável posto que é essencialmente subjetivo - tem tornado as discussões sobre a narratividade ainda mais desafiadoras. A meu ver, tendo empreendido até agora duas obras ficcionais que ofertam modalidades narrativas diversas - uma em primeira pessoa, obra que discutirei doravante, e outra em terceira, A Alcova da Morte (Editora Avec, 2017) -, esta escolha está na própria base do fazer literário. Tal reflexão, ao contrário de nos afastar da pergunta central a toda investigação criativa - "De onde as ideias surgem?" -, nos aproxima ainda de uma possível resposta, uma vez que a preocupação com o narrar e sua(s) voz(es) revela-nos alguns dos mais importantes percalços e desafios presentes na criação de uma obra ficcional.
Neste ensaio, discutirei a criação de Brasiliana Steampunk, série literária publicada pela editora LeYa e associada aos modos narrativos conhecidos como ficção científica, horror e/ou fantasia. Além de constituir uma obra de cunho popular, direcionada ao público adulto e jovem adulto, Brasiliana Steampunk ambiciona revisitar criticamente a tradição literária oitocentista, podendo não apenas fomentar a leitura entre jovens leitores, em especial estudantes de ensino médio, como também recriar estilística e ficcionalmente os autores e obras da nossa tradição. Nesse sentido, é a questão das vozes literárias criadas e recriadas para esta narrativa que pretendo discutir neste texto.

Para tanto, partirei da discussão sobre o processo de criação da série e da composição do seu primeiro volume, A Lição de Anatomia do Temível Dr. Louison (2014), à luz de três fenômenos culturais atuais: a utilização de obras em domínio público para fins ficcionais inéditos, a justaposição de diferentes personagens e situações advindas de diferentes obras num único universo e a utilização da estética steampunk. Em um segundo momento, discutirei como procedi em termos textuais na recriação dos heróis literários criados por Álvares de Azevedo, Machado de Assis, Aluísio de Azevedo e Lima de Barreto, entre outros, e como se deu a realocação desses heróis no cenário da série, a retrofuturista capital sulista Porto Alegre dos Amantes. Por fim, refletirei como esse trabalho de recriação de vozes literárias preexistentes na primeira metade do romance me levou ao desenvolvimento de três personagens inéditos na segunda, a saber o investigador Pedro Britto Cândido, a escritora feminista Beatriz de Almeida \& Souza e o médico e esteta que dá título do livro, Antoine Louison. 


\section{Domínios públicos, universos compartilhados e visões retrofuturistas: as bases para a criação de Brasiliana Steampunk}

Nas últimas décadas, especialmente em países como Estados Unidos, França e Inglaterra, temos testemunhado três fenômenos literários e culturais instigantes, fenômenos esses que estão na própria gênese da criação de Brasiliana Steampunk. O primeiro deles é a reutilização de personagens literários clássicos, atualmente em domínio público, em contextos modernos ou mesmo históricos tradicionais. A lei do domínio público no que concerne à literatura estabelece que, na maioria dos países, após setenta anos da morte do seu criador, personagens, situações e enredos, passam a ter propriedade livre podendo ser utilizadas por qualquer artista, do próprio país ou fora dele. Nesses casos, apesar de não haver mais o direito de propriedade intelectual, prevalece o direito moral, o que significa que sua autoria sempre deve ser mencionada. As mesmas diretrizes, com exceções mínimas, são também vigentes no Brasil e em Portugal (GUEIROS, 2005). ${ }^{1}$

Com muitas obras produzidas no século 19 passando a domínio público nas últimas décadas, uma série de personagens e de obras clássicas foram revisitadas e recriadas em obras inéditas voltadas muitas vezes a públicos diferentes de suas contrapartes originais. Um caso ilustrativo desse fenômeno e de seu potencial é a obra de Arthur Conan Doyle, cuja dupla

\footnotetext{
Boa parte das leis que prescrevem a utilização de obras, personagens e histórias foram estabelecidas ainda em 1886 na Convenção de Berna, conversão suíça na qual se definiram especialmente as questões que dizem respeito à proteção de obras artísticas, intelectuais e literárias. Para consultar o documento em português, entre outras línguas, disponibilizado na página da UNESCO, acessar $<$ https://goo.gl/b1vGs1>.
}

de detetives John Watson e Sherlock Holmes tem sido reutilizada tanto no caso de obras audiovisuais quanto literárias. No caso dessas, destacamos $A$ slight trick of the mind (2005), do norte-americano Mitch Cullin, transformado em filme em 2015, La sabedúria de los muertos (2004), do espanhol Rodolfo Martínez, e $O$ xangô de Baker Street (1995), de Jô Soares.

No caso do audiovisual, temos três fenômenos bem diversos e igualmente exemplares do potencial da recriação de obras em domínio público, todas lançadas em 2010. Primeiro, estreou nos cinemas o filme Sherlock Holmes, dirigido pelo inglês Guy Ritchie, filme que ganhou continuação anos depois e cuja proposta era revisitar a dupla de detetives - vivida na película por Robert Downey Jr. e Jude Law - no período vitoriano. No mesmo período, Robert Doherty produzia Elementary, série televisiva que atualizava a história do detetive para os tempos modernos na cidade de Nova York e trouxe Jonny Lee Miller no papel de Holmes e a atriz Lucy Liu no papel de Watson. Também na televisão, Steven Moffat e Mark Gatiss fizeram o mesmo, porém situando a trama em Londres e contando com Benedict Cumberbatch e Martin Freeman na pele dos dois investigadores.

Tais reinterpretações de obras em domínio público têm no mínimo três efeitos. Primeiramente, solidificam um determinado personagem ou obra, fortalecendo seu caráter canônico ou clássico, mesmo no caso de uma obra como a de Doyle, de grande caráter popular. Em segundo lugar, tais recriações reavivam o interesse pela obra original em uma audiência que já a consumiu e/ou que volta a consumi-la após reencontrá-la num contexto/mídia diferente da do original. Por fim, esse 
exercício de produção inédita, além de sua óbvia utilização mercadológica, também cumpre o papel de apresentar a obra ou o autor a uma audiência que de outro modo talvez não chegasse a eles, o que é visivelmente perceptível especialmente em projetos audiovisuais.

Ao lado desse fenômeno, há um segundo, que é o da união de personagens e/ou histórias criadas em obras diferentes e aglutinadas num universo conjunto. A partir dessa perspectiva, pode-se imaginar um universo hipotético no qual personagens criados por diferentes autores poderiam coexistir, habitando uma mesma paisagem ficcional. A partir de uma ideia de crossover - fenômeno comum nas histórias em quadrinhos, quando dois ou mais personagens de diferentes séries são colocados ao lado de outros para intensificar vendas ou conquistar novos leitores -, uma série de autores e autoras tem recorrido a este recurso com resultados profícuos e não raro instigantes. Como muitas vezes esse tipo de criação posiciona seu enredo no passado, nos estudos literários o fenômeno tem sido tratado a partir dos conceitos de "história alternativa" ou "ucronia". ${ }^{2}$

Para exemplificar esse tipo de procedimento, destaco três casos de justaposições de heróis literários advindos de fontes variadas e reposicionados em um mesmo universo ficcional. Primeiro, o romance de Kim Newman, Anno Dracula (1992), no qual o autor inglês questiona o que teria acontecido caso o conde Drácula tivesse vampirizado a rainha Vitória, numa trama que brinca com diversos personagens históricos e ficcionais do final do século XIX. Outro caso bem conhecido é a

2 Para uma discussão sobre os dois termos, ver Fondanèche (2006) e Girardot e Méreste (2006).
League of Extraordinary Gentlemen (1999), história em quadrinhos roteirizada por Alan Moore e desenhada por Kevin O'Neill. ${ }^{3}$ Nela, um grupo de heróis formado por Mina Harker, Allan Quaternain, Capitão Nemo e Mr. Hyde, entre outros monstros literários vitorianos, confrontam uma série de ameaças ao Império Britânico. Recentemente, a série televisiva Penny Dreadful (2014-2016), criada por John Logan, fez o mesmo exercício, ampliando o escopo de personagens e recorrendo até ao Dr. Victor Frankenstein criado por Mary Shelley e a outros monstros clássicos como lobisomens e bruxas. ${ }^{4}$

Por fim, o último fenômeno que levaria à escrita de Lição de Anatomia é a estética ou modo narrativo conhecido como Steampunk. No decorrer da década de 1980, muitos escritores de ficção científica e fantasia reinterpretaram o espírito "punk" da década anterior, enfatizando cenários insólitos, realidades alternativas e fantasias alocadas no passado ou no futuro. Um elemento central a essas histórias era a presença de heróis marginais, páreas sociais e minorias étnicas que pouco espaço ganhavam em exemplares do gênero nas décadas anteriores, uma vez que seus respectivos autores ainda preferiam heróis caucasianos idealizados, vítimas femininas em perigo e ameaças malignas, de preferência de origem intergaláctica ou oriental. Na contracorrente dessa produção, três autores estadunidenses passaram a produzir histórias nas quais a revisão fantástica do passado preconizou problemas sociais e reflexões políticas pertinentes ao seus tempos (ROBB, 2012).

\footnotetext{
Para uma discussão sobre essas obras, ver Vandermeer e Chambers (2011).

4 Para análise da recriação dos monstros clássicos utilizados por John Logan em Penny Dreadful, ver Tavares e Matangrano (2016).
} 


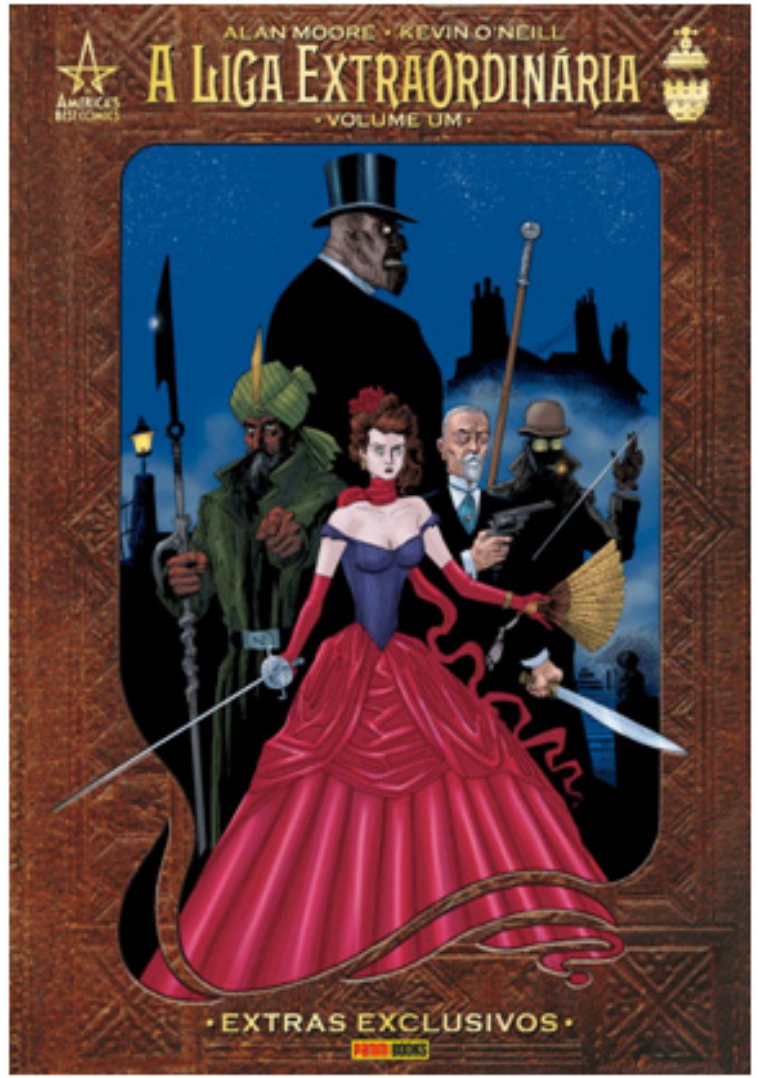

Figura 1. Capa de The League of Extraordinary Gentlemen

Como autores de ficção científica e fantasia, esses escritores já nutriam uma série de desafetos com o cenário literário acadêmico norte-americano, muito mais receptivo a obras de temática urbana e existencial do que à exploração de mundos fantásticos, preconceito diminuído nos últimos anos tanto nos EUA como também no Brasil. O caráter marginalizado de sua produção fez esses autores buscarem uma recriação do período vitoriano centrada menos em lordes e damas e mais em párias sociais que se multiplicavam na Londres finissecular do XIX. Neste sentido, de grande auxílio foi a obra jornalística London Labour and the London Poor (1851), de Henry

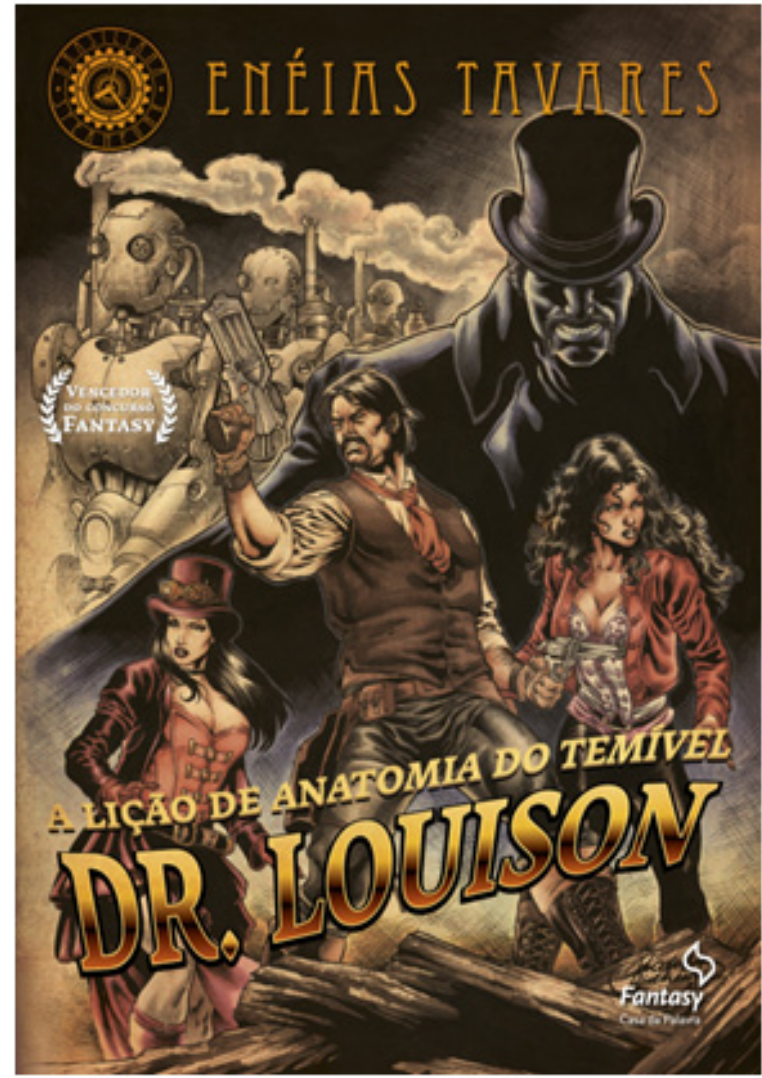

Figura 2. Capa de A Lição de Anatomia do Temível Dr. Louison

Mayhew (VANDERMEER e CHAMBERS, 2011).

Desse contexto, resultaram três romances e seus respectivos protagonistas marginalizados ou em contato com páreas sociais: o viajante Edwin Hocker e os moradores subterrâneos recriados do romance de H. G. Wells, em Morlock Night (1979), de K. W. Jeter, o inexpressivo professor Brendan Doyle, de Anubis Gates (1983), de Tim Powers, e o explorador cientista Langdon St. Ives, presente em Homunculus (1986), de James Blaylock. Um ano depois da publicação da última obra, em abril de 1987, na seção de cartas da revista de ficção científica Locus, um 
deles criaria o termo que definiria suas "fantasias vitorianas": Steampunk.

Nas últimas décadas, o steampunk enquanto fenômeno se tornou comum em obras literárias - em especial no caso de autores como Stephen Hunt, Gail Garriger e Stott Westerfeld, para falarmos apenas dos já publicados no Brasil -, em estéticas cinematográficas e televisivas como na versão cinematográfica da League of Extraordinary Gentlemen, dirigida por Stephen Norrington em 2003, ou em The Wild Wild West, dirigido por Barry Sonnenfeld em 1999 -, na produção de música alternativa - como no caso das bandas Abney Park e Beats Antique - ou mesmo no mundo da moda - como atestam diversas coleções criadas por Alexander McQueen (VANDERMEER e BOSKOVICH, 2014). Além desses, poderíamos citar diversas obras em quadrinhos, além de jogos analógicos e digitais, que têm bebido senão da temática do gênero então de seu visual.

No Brasil, a publicação de antologias dedicadas ao tema - como Steampunk Histórias de um passado extraordinário (TARJA, 2009) e Vapor Punk (DRACO, 2010) - já atestavam um primeiro interesse. Entretanto, foi com a criação do Conselho Steampunk - grupo de aficionados de diversos estados brasileiros - e a partir da organização da SteamCon de Paranapiacaba (SP), evento que já está em sua quinta edição, que a estética se solidificou em nosso país. ${ }^{5}$

Foi a partir desses três fenômenos - a utilização de obras em domínio público, a alocação de diferentes personagens num mesmo universo ficcional e o verniz

\footnotetext{
Para uma discussão do fenômeno steampunk em nosso país a partir dos grupos de fãs e entusiastas, ver Pegoraro (2012 e 2014).
}

steampunk - que comecei a pensar na obra que daria origem a Brasiliana Steampunk. Com base em um conto escrito em 2009, expandido em novela no ano seguinte, que tinha o mesmo título do romance e que trazia dois personagens inéditos - um sofisticado assassino em série confrontando um investigador solitário e endurecido pelos anos de serviço -, percebi que poderia não só usar personagens da literatura brasileira para contar essa história, recorrendo às vozes narrativas canônicas para dar conta do mundo e dos acontecimentos ao redor do enredo principal, como também alocar essas vozes num mesmo cenário, o que produziria um singular - ao menos nos padrões nacionais - exercício intertextual.

Foi a partir dessa hipótese que cheguei à ideia de utilizar Isaías Caminha, personagem criado por Lima Barreto, chegando a Porto Alegre para escrever uma reportagem sobre os crimes de Louison, então internado num hospício sob a direção de Simão Bacamarte - presente em $O$ Alienista, de Machado de Assis. Ao lado desses ícones, teria outros cenários que reuniriam também personalidades literárias. De um lado, o Palacete dos Prazeres, prostíbulo de luxo frequentado por Louison e suas vítimas, sob a administração de Rita Baiana, Léonie e Pombinha - personagens retiradas de $O$ Cortiço, de Aluízio de Azevedo. Do outro, uma sociedade secreta chamada Parthenon Místico - numa alusão ao Partenon Literário que existiu em Porto Alegre no século 19 -, formada pelos aventureiros do oculto Sergio e Bento Alves (O Ateneu, de Raul Pompeu), pelo cientista Doutor Benignus (criado por Augusto Emilio Zaluar no romance homônimo), pela médium indígena Vitória Acauã (Contos Amazônicos, de Inglês de Souza) e pelo imortal satanista Solfieri (Noite da Taverna, de Alvares de 
Azevedo). Além disso, estariam presentes na narrativa a Luneta Mágica - criada por Joaquim Manuel de Macedo - e A Ilha do Desencanto - cenário criado por Apeles Porto Alegre no romance Georgina.

Quanto à estética steampunk, com sua linha temporal alternativa e seus zepelins vaporentos, autômatos ultramodernos, utensílios místicos \& ferramentas tecnológicas impossíveis, ela seria contrastada com pesados capotes e vestidos requintados, alocando a narrativa num frio e chuvoso cenário gaúcho. Tal exercício hipotético me fez não apenas redefinir a linha temporal de sua capital, como também a de todo o Brasil, situando, por exemplo, a abolição da escravatura dez anos antes, devido à substituição da mão de obra escrava pela tecnologia robótica, o que resultaria em uma série de situações intrigantes.

Quanto à cidade em si, ao invés de Porto dos Casais, antigo nome de Porto Alegre, teríamos Porto Alegre dos Amantes, uma versão mais sensual, verdejante e selvagem do que sua contraparte real. A partir do mapa comemorativo da cidade, produzido em 1916, redefini a cartografia da cidade, substituindo o Lago Guaíba pelo Pântano do Guaýba, o Parque da Redenção pelo Bosque da Perdição e o bairro Menino Deus pelas cercanias do Menino Diabo, entre outas realocações que repensavam a própria cartografia da cidade (Fig. 3). ${ }^{6}$

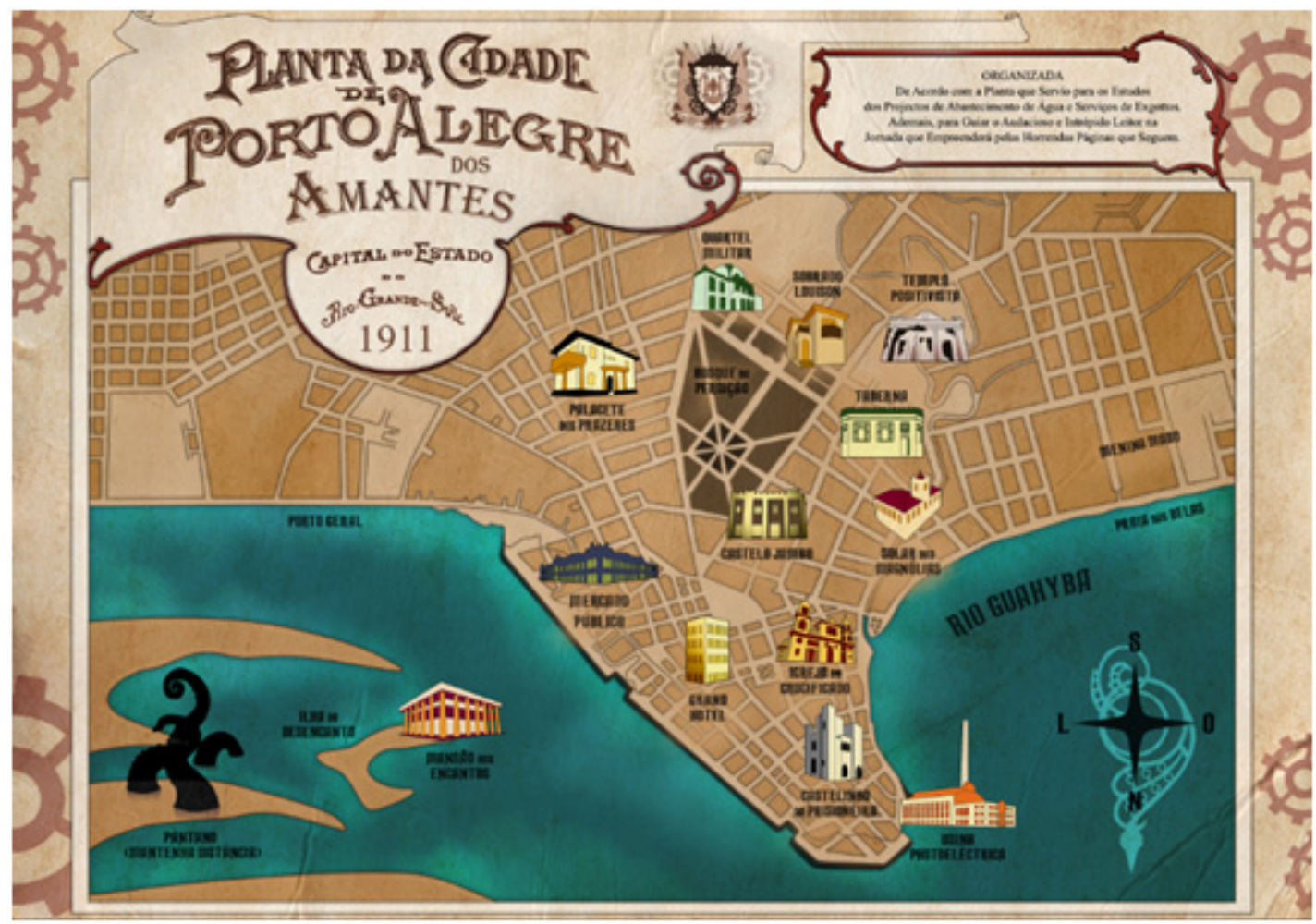

Figura 3. Mapa de Porto Alegre dos Amantes por Jéssica Lang

\footnotetext{
6 Em 2016, produzimos o "Passeio Turístico por Porto Alegre dos Amantes, com Vitória Acauã", um audiodrama inédito e gratuito, que pode ser acessado em <https://goo.gl/3Af1dZ>, junto ao mapa produzido para a série, de autoria de Jessica Lang.
} 
A partir dessa construção inicial, comecei o longo trabalho de recriação das vozes literárias preexistentes, trabalho que alteraria substancialmente as vozes literárias já presentes no conto de 2009, bem como resultariam em uma personagem inédita: a escritora negra Beatriz de Almeida \& Souza. É a respeito desse trabalho de organização narrativa e estilística que me dedicarei a partir deste ponto.

\section{Heróis, alienistas \& cafetinas: a recriação de vozes literárias clássicas em Brasiliana Steampunk}

Meu primeiro esforço esteve em definir quais personagens da tradição literária brasileira iria utilizar e quais não, num exercício que foi menos dedicado a qualquer critério de importância ou popularidade literária e mais à adequação desses heróis e heroínas ao que o enredo necessitava. Após definir isso, cheguei à versão final dos personagens que usaria, montando uma tabela que não apenas informasse os anos de publicação de suas respectivas obras como também a idade suposta que esses personagens teriam nas obras em que apareceram pela primeira vez e sua respectiva faixa etária em 1911, ano do enredo principal de Lição de Anatomia (Tabela 1).

Esse cálculo, e seu resultante conjunto de idades dos respectivos narradores, auxiliaria inicialmente a definir o tom das diversas vozes que comporiam o mosaico narrativo do romance. Nesse sentido, não desejava apenas utilizar os nomes desses personagens - fazendo-os discursar de forma una, o que falsearia justamente a polifonia de seus estilos, visões de mundo, vocabulários, etc, ou simplesmente fazendo-os falar em tom moderno, distante de suas contrapartes literárias. Antes, o que esperava empreender era a recriação tonal das vozes literárias que Ihe haviam originado, numa homenagem não apenas aos nomes, ocorrências e situações criadas por seus autores originais, como também às escolhas narrativas de cada um deles.

A dificuldade desse exercício esteve em abrir cada um desses volumes e estudar seus conjuntos semânticos, estruturas frasais, construções adjetivas e adverbiais, além de quebras narrativas e mesmo estilísticas, o que muitas vezes resulta naquilo que mal ou bem denominamos "estilo". No caso de autores que deram

Tabela 1. Personagens Recriados em Lição de Anatomia e Idades Hipotéticas

\begin{tabular}{|c|c|c|c|c|}
\hline Personagem \& Suposto Nascimento & Criado por & Ano de publicação & $\begin{array}{l}\text { Idade no ano } \\
\text { de publicação }\end{array}$ & Idade em 1911 \\
\hline Solfieri de Azevedo (1836) & Aluízio de Azevedo & 1855 & 19 & 75 \\
\hline Doutor Benignus (1832) & Augusto Emílio Zaluar & 1875 & 50 & 79 \\
\hline Simão Bacamarte (1822) & Machado de Assis & 1882 & 60 & 89 \\
\hline Sergio Pompeu (1877) & Raul Pompéia & 1888 & 11 & 33 \\
\hline Bento D’Avila (1870) & Raul Pompéia & 1888 & 18 & 41 \\
\hline Rita Baiana (1868) & Aluízio de Azevedo & 1890 & 22 & 43 \\
\hline Pombinha (1878) & Aluízio de Azevedo & 1890 & 12 & 33 \\
\hline Senhorinha (1887) & Aluízio de Azevedo & 1890 & 03 & 24 \\
\hline Léonie (1858) & Aluízio de Azevedo & 1890 & 32 & 53 \\
\hline Vitória Acauã (1881) & Inglês de Souza & 1893 & 12 & 30 \\
\hline Isaias Caminha (1881) & Lima Barreto & 1909 & 28 & 30 \\
\hline
\end{tabular}


voz narrativa aos seus heróis, construindo a própria trama em primeira pessoa - como Lima Barreto ou Álvares de Azevedo - esse estudo foi mais direto, dada a extensão textual dessas narrativas. Por outro lado, no caso de autores que utilizaram a terceira pessoa, como Aluísio de Azevedo e Machado de Assis fizeram em O cortiço e em $O$ alienista, tratava-se de encontrar e decompor analiticamente os diálogos específicos dos personagens em questão.

Separei aqui três exemplos - entre muitos outros - que são ilustrativos dessa recriação e dos resultados obtidos. Neste caso, escolhi Isaías Caminha, Simão Bacamarte e Rita Baiana, especialmente por exemplificarem de forma pontual as diferenças estilísticas resultantes do construto polifônico de Brasiliana Steampunk. No caso do jornalista carioca, eu parti da ideia de que Lição de Anatomia contaria o que aconteceu depois da narrativa de Lima Barreto, como se o universo fornecesse continuidade a vários construtos ficcionais de nossa tradição, decisão que por fim se estendeu aos demais personagens da série e ao próprio projeto dos volumes seguintes. Tal decisão também resultou no principal interlocutor de Caminha: o editor Loberant, a quem o jornalista enviaria o conjunto dos documentos reunidos no Caso Louison, como se o romance registrasse, no nível ficcional e organizacional, numa espécie de Livro Reportagem sobre os crimes do "Estripador da Perdição".

No aspecto estilístico, Isaias remeteria a construções frasais bem próximas do livro de Barreto, muitas vezes recorrendo a grupos semânticos semelhantes e a expressões usadas com sintomática repetição. Nesse trabalho, não raro recorri a construtos argumentativos bem próximos do texto de Barreto, que muitas vezes interrompe a narrativa para longas digressões reflexivas, aspecto da própria personalidade do herói narrador que queria manter em minha própria versão do jovem jornalista. Pela proximidade do estilo decadentista ou ultrarromântico, ampliei o escopo impressionístico de Caminha, tornando-o ainda mais sensível e suscetível aos acontecimentos vivenciados naquela surpreendente paisagem sulista. ${ }^{7}$ $\mathrm{O}$ excerto que ilustra alguns desses elementos pertence à abertura do livro, quando o jornalista chega ao cenário de sua investigação:

Diante dos olhos, as coisas do mundo, e todas elas penetravam em mim.

Com uma volúpia que me era estranha, cerrei os olhos ao pântano abaixo, às suas pequenas embarcações marítimas, paradas na linha do porto, aos bondes eléctricos que iam e vinham no tracejado das ruas diminutas, aos pontos de luz que explodiam em infinitos feixes, à cidade que se ofertava como dama sombria, no requinte do tafetá bordado, nos traços de sua maquilagem, na obscenidade de seus segredos. Como a contemplar um corpo desejado, vigiei a paisagem urbana e almejei seus perfumados enigmas, suas curvas arquitetônicas, suas sombras candentes. Do alto da nave, duas cidades-irmãs se exibiam orgulhosas, gêmeas malditas. Uma real, outra imaginária, liquefeita no espelho d'água do Guayba (2014, p. 21).

No caso do médico alienado criado por Machado de Assis, o primeiro problema a ser resolvido era a idade do personagem, uma vez que o narrador de $O$ alienista o apresenta como tendo vivido "há muito tempo atrás". Tal problema foi resolvido

\footnotetext{
Para uma análise de Lição de Anatomia e seu diálogo com a tradição decadentista, especialmente no caso da construção da personagem Isaías Caminha, ver MATANGRANO, 2016, disponível em <https://goo.gl/ RD4rNa>.
} 
fazendo o próprio protagonista, no início da segunda parte do livro, explicar que "o principal exemplo da loucura coletiva" de Itaguaí "foi o fato de terem associado" sua "existência a um período muito anterior ao verdadeiro (...)" (2014, p.63). Com esse problema resolvido, fiz o doutor, após abandonar seu ofício desastroso no hospital Casa Verde, mudarse para Porto Alegre dos Amantes, onde foi escolhido para administrar o Asilo São Pedro para Criminosos Insanos e Histéricas Descontroladas.

Como meu objetivo com Lição de Anatomia era também ressaltar uma série de elementos de cunho social e crítico que ainda precisam ser pensados e debatidos, mesmo em nossa sociedade contemporânea, fiz de Simão Bacamarte um exemplar de muitas das grotescas ideias que pulularam no imaginário europeu e também americano na primeira metade do século XX, fazendo defender a Eugenia e o Racismo, enquanto o fazia promulgar opiniões misóginas e abjetas a qualquer mentalidade moderna. Como a ironia machadiana está entranhada em nossa mentalidade e, portanto, em nossa discursividade, os capítulos narrados por Simão resultam em construções frasais tortuosas, entremeadas às altissonantes e absurdas opiniões do doutor sobre si próprio e seu pretenso trabalho humanístico, além do ridículo egocentrismo tão comum aos personagens machadianos - especialmente os masculinos. $\mathrm{O}$ excerto ilustra isso, ao mostrar o passeio do médico por uma das alas do asilo.

Ao caminhar pelos infindos corredores do asilo e visitar suas múltiplas alcovas, meu peito infla de orgulho pelo trabalho realizado. Dividi o asilo em quatro blocos, que correspondem não aos diferentes tipos de doenças aqui medicadas, mas aos benéficos e espantosos tratamentos possibilitados pela química moderna e pela tecnologia mecânica.

$\mathrm{Na}$ primeira dessas alas, cadeiras e camas eléctricas garantem o conforto dos violentos e a segurança dos visitantes e alcaides. Em geral, mais a segurança dos últimos, visto serem raras as visitas que recebemos no São Pedro. Em tais cômodos e leitos, devidamente desinfetados dos infectos prévios, os sorumbáticos são depositados para tratamento diário, por minutos ou horas, dependendo da gravidade do distúrbio e da paciência do devotado plantonista. (2014, p. 67).

A fim de contrastar com essas duas vozes masculinas tão características - uma jovial e romântica e outra mais madura e cínica, senão insana - Lição de Anatomia é perpassado de vozes femininas, sendo a grande maioria também de origem literária. Como contraponto ao decadentismo um tanto ingênuo de Caminha, Vitória Acauã - a personagem criada por Inglês de Souza - acabou se tornando uma voz mais forte e madura, trazendo também à narrativa muito do verniz místico presente ainda no relato de Contos Amazônicos. Mas são as damas do Palacete dos Prazeres, administrado pela tríade criada por Aluísio de Azevedo, as principais responsáveis pelo mural feminino polifônico da primeira metade do romance.

Em contraste com a linguagem mais racional e sóbria de Léonie e o discurso mais suntuoso e requintado de Pombinha, é em Rita Baiana que encontramos um dos exemplares de oralidade mais marcantes do livro. Rita não escreve cartas porque não gosta e porque não sabe (2014, p.115), ditando suas mensagens a Senhorinha através de um secretário robótico. Tal 
expediente narrativo - o registro da mensagem oral através de um dispositivo mecânico - terá especial importância no desenvolvimento do romance, por vezes substituindo o relato escrito - seja em cartas ou diários - por gravações de monólogos ou diálogos. No caso de Rita, o primordial foi recuperar dos diálogos de $O$ cortiço a espontaneidade de sua fala, a leveza e a dança de suas construções frasais.

Espero que sua mágoa da Rita, por ter desgraçado seu velho pai e sua mãe, Piedade, coitada, tenha passado. Eu fiquei triste quando me contô que a coitada tinha batido as botas de tanto beber. Triste mesmo, pois lembrava que era sua mãe e que ocê devia tá triste. Maldita cachaça, que acaba com a vida da gente que é fraca. Mas ocê não é fraca, não é minha linda? Ocê é como a Rita aqui, que eu te conheço, forte que nem pedra, que quebra a marreta mas que não se deixa quebrá.

Aqui em Porto dos Amantes - acho esse nome tão bonito - tudo segue bem. O palacete acabô de se torná a mais afamada casa da cidade. Eu e as outras duas tamos ricas... daqui a pouco até pensamos em viajá pras Europa... a Léonie, que já viveu em Paris, diz que a gente tem que ir lá. Eu tô bem aqui... não quero viajar mais. Quero apenas um amor que me faça sambá uma ou duas vezes por semana, um amor que me faça lembrá do que gosto (2014, p. 116).

A mesma atenção à linguagem foi extensível a outros personagens literários do romance, como Vitória Acauã, Solfieri, Benignus, Sergio e Bento Alves, apesar desses resultarem em expedientes diversos e menos importantes ao enredo principal do livro, resultando mais em participações especiais. Como muitos deles aparecerão em futuros volumes da série ou em contos, trata-se de um trabalho em curso, ainda a ser definido à medida que histórias protagonizadas por esses personagens merecerem maior atenção, como é o caso de O Parthenon Místico, volume que terá por protagonistas justamente os heróis criados por Raul Pompeia.

É este mosaico literário o responsável por conduzir o leitor de Lição de Anatomia até a metade do livro, apresentando seus personagens, descrevendo seus espaços, informando o enredo e comunicando muitos dos temas sociais caros aos habitantes desta Porto Alegre alternativa. A partir delas é que encontrei as vozes dos três protagonistas inéditos do livro, heróis cuja construção narrativa e estilística passo a discutir agora.

\section{Investigadores severos, temíveis doutores e escritoras feministas: a criação de vozes literárias inéditas de Lição de Anatomia}

Ainda em 2009, no conto que daria origem ao romance, o conflito era definido pelo embate entre uma visão monocromática de justiça - representada pelo policial Pedro Cândido - e uma perspectiva mais elaborada, que tinha na amoralidade estética sua principal frente de defesa - neste caso, defendida por um criminoso educado e articulado. À época, essas duas vozes narrativas me desagradavam especialmente pela falta de clareza como essa discussão, que constituía o tema central da história, era apresentada. Além das variações estilísticas, faltava a Louison as razões que tornariam seus crimes minimamente defensáveis a partir de qualquer perspectiva.

Na reescrita do texto e na transformação de um conto de menos de dez mil palavras 
em um romance com mais de setenta mil, o fato da primeira metade ser narrada por personagens externos à dupla protagonista obrigou-me a olhar para eles a partir de uma perspectiva diferente daquela buscada inicialmente. Agora, o fato de obrigar Isaías a investigar a origem criminosa de suas pretensas vítimas como também de demonstrar - via Simão Bacamarte que havia lobos mais ferozes no bosque selvagem de Porto Alegre dos Amantes foi pouco a pouco transmutando Louison de assassino frio em justiceiro social, apesar da primeira perspectiva nunca ter sido desmentida por nenhum dos personagens, nem pelo próprio.

Esta escolha se deu justamente para evitar uma simplória dicotomia que transformasse o mal em bem, resolução tão comum em histórias folhetinescas ou super-heroicas. Neste caso, eu queria primeiro expandir o mistério: que não seria o tradicional "Quem matou" e sim "Quais seriam as razões" que levaram este esteta e humanista a cometer os crimes dos quais era acusado. Além disso, fazer com que o "temível doutor" mantivesse o epiteto, mesmo depois de alquebrado pelo "tratamento médico" administrado por Simão Bacamarte no Asilo São Pedro e mesmo após suas razões serem em tudo esclarecidas, tornaria, esperava eu, a narrativa mais coerente e verossímil. No cerne deste mistério estaria a "secretária negra" de Louison, a escritora feminista Beatriz de Almeida \& Souza. Mas antes de dar voz a ela, último capítulo a ser escrito - apesar de figurar o penúltimo do livro - precisaria então resolver as vozes do investigador severo e do refinado médico assassino.

Nas últimas três partes do romance, que constituem a segunda metade do livro, eu recorri à instância da gravação de uma entrevista, o que me auxiliaria a dar voz a esses personagens, não como eles escrevem e sim como eles falam uns com os outros. No caso do primeiro, o investigador Pedro Britto Cândido foi escrito numa linguagem mais direta e primitiva, centrada em substantivos concretos e numa esparsa utilização de adjetivos e advérbios. Suas falas compreenderiam períodos curtos que teriam o impacto de um tiro. $\mathrm{O}$ contato afetivo de Cândido com Rita Baiana no transcurso da terceira parte também auxiliou a definir quem era essa personagem.

Tanto Cândido quanto Rita tem um modo mais simples e direto de existirem e, portanto, funcionarem no mundo ao seu redor, afeitos às opulências e aos excessos. Ademais, a visão monocromática do investigador e sua justiça básica, centrada numa imperfeita e simplista, porém admirável, noção de bem e mal, foi adensada a tal modo que o próprio herói pudesse concluir - a partir do que viu e descobriu, tanto de Louison quanto do histórico de suas vítimas - que sua visão existencial não mais dava conta da complexidade que havia acessado. Fazê-lo narrar, em tempo real, como ele viu a história nos meses anteriores, objetivava comunicar, em termos discursivos, aqueles raros e caros momentos nos quais nos damos conta de uma verdade que sabíamos, mas que denegávamos em razão de restrições sociais, preconceitos pessoais ou idealismos existenciais. Segue um excerto de Cândido no qual ele narra ao entrevistador/leitor o percurso de suas investigações.

Me anojava aquilo tudo. Era uma coletânea de gostos culinários, raridades gastronômicas, degustações de bebidas, 
espetáculos teatrais, bailes de salão, tudo o que os ricaços desocupados adoram fazer. Eu, que sempre fui feijão com arroz e carne, na companhia de um copo gelado de cerveja, achava aquilo tudo uma frescura, quando não um escândalo. Mas o que dava ânsias não era só isso. Eram as vidas privadas daquela gente. Os desaparecidos deixavam atrás de si um rastro medonho de merda. Amaral, por exemplo, quase sempre junto com Torres, que só assistia, pois era muito gordo para qualquer outra atividade, adorava praticar zoofilia. Zoofilia? Mas, insisto, o problema não é esse, pois cada um sabe o que faz e... ah! Nossa Senhora! Há um limite, ora bolas! Zoofilia? Como minha velha mãe sempre disse: um mundo perdido esse nosso, completamente perdido (2014, p. 195)

Na outra ponta da balança narrativa, estaria Louison, que já havia dado mostras de seu vigor discursivo em outras passagens do livro, tanto em seu encontro com Isaías Caminha, acorrentado como estava no Asilo São Pedro na primeira parte do livro, quanto na sua fala hipnótica e vertiginosa diante de Simão na segunda, com um solilóquio construído de encontros consonantais em " $t$ " e " $r$ ", que levaram o alienista a perder a própria consciência. Por outro lado, no Interlúdio Dramático entre as partes 4 e 5, acessamos sua própria narrativa dos crimes, num discurso mais próximo do que esperaríamos de um homicida em série.

Mas agora, a partir do encontro com Cândido e fechando todas as janelas e portas narrativas abertas nas partes anteriores, finalmente poderíamos ter acesso a Louison e às suas explicações, tanto aos dois personagens que estão com ele no clímax do romance como também aos leitores. Ao pensar em Louison e sobretudo na sua linguagem, na forma como ele narraria a vida e o cosmos circundante, pensei inicialmente num personagem que olhasse o mundo a partir de uma perspectiva essencialmente filosófica e artística, pouco centrada nas relações humanas e suas fugidias interações e mais nas grandes questões epistemológicas a respeito da essência da alma humana, do belo e de suas implicações para discussões morais e éticas.

A partir dessa perspectiva, não queria multiplicar meramente adjetivos e advérbios ou produzir períodos excessivamente elaborados, o que já tinha feito em certa medida com Isaías Caminha e também no Interlúdio, texto no qual Louison mais encena o que deseja que pensem de seus crimes do que revela quem realmente é. Assim, essas narrativas anteriores deram lugar a uma discursividade em tudo organizada e cuidadosa, não apenas explicando ao(s) seu(s) interlocutor(es) os mistérios que permaneciam ainda sem solução como especialmente elucidando sua complexa visão existencial. Neste caso, depois de uma longa digressão sobre o bem, o mal e a amoralidade da arte, é no tigre blakeano que Louison encontrará seu desfecho argumentativo. Em outros termos, é no poeta inglês que ele encontrará o fechamento adequado à sua inusitada lição de anatomia.

Blake escreveu sobre a assombrosa simetria presente no brilho em chamas do olho do tigre, o mesmo tigre que assassina lobos e homens. Se este é um mundo de Deus, meu caro amigo, no mínimo Ele está bem, bem longe. Ou então, Ele não se importa. Mas deixeme, por favor, terminar o meu ponto. O que quero deixar claro é que não há relação direta entre justiça e moralidade. E nisso está a validade da arte. Nela, pode-se desprezar as convenções sociais, as crendices religiosas, os panfletos políticos e partidários, o tipo 
de ideia perniciosa que nos faz crer que há uma evolução no homem, tanto física quanto cultural. Nenhum desses tópicos interessa à arte. Se há algo do qual ela trata, é daquilo que somos em toda a nossa animalidade. Numa Bíblia, eu deveria estar onde tu estás e tu terias um céu de portões prateados à espera de tua chegada e anjos cantando em revoada sobre a entrada de um justo nos reinos celestes.

Mas não é isso o que vai acontecer.

Não há céus nos esperando, nem infernos.

Há apenas o brilho dos olhos do tigre abaixo do firmamento.

[A música para] (2014, p. 281-282).

Em resposta a esses dois discursos antitéticos, a quinta parte do romance, dá voz à personagem Beatriz de Almeida \& Souza, amante de Louison e escritora feminista que por fim responde à boa parte dos enigmas envolvendo os motivos de seus crimes. Nela, busquei inicialmente responder o que significaria ser uma mulher negra numa sociedade recém libertária e misógina, não tendo familiares ou conexões sociais que a colocariam no caminho profissional desejado, como uma escritora. Beatriz faz isso forjando uma identidade masculina, Dante D'Augustine, como tantas autoras do século 19 fizeram a fim de garantir a publicação de seus textos.

A frase inicial usada por ela - "Meu nome é Beatriz de Almeida \& Souza e eu sou filha de escravos." (2014, p. 231) abriu diversas possibilidades tanto ficcionais quanto tonais, tanto no que concerne à questão do gênero no período, como também a importantes e ainda relevantes questionamentos sobre representatividade, preconceito étnico e violência, tanto literal quanto simbólica. Além disso, encontrei em Beatriz, dada a sua carreira como escritora, uma oportunidade de comunicar minha fascinação com o potencial das histórias em ensinar, comover e fortalecer seres humanos em condições limítrofes, sejam elas sociais, morais ou mesmo físicas. Num romance composto de dezenas de outros romances, criar uma personagem para quem as histórias são fundamentais enquanto fortalecimento existencial tornou-se, no meu caso, como escritor e professor de literatura, para não dizer leitor fervoroso, uma grata surpresa. Refletindo sobre sua própria biografia e sua carreira como escritor/ra, eis o que Beatriz revela ao leitor/ra, dando ao livro um verniz também metaficcional: trata-se de um romance de crime que questiona os próprios parâmetros constitutivos desse modo narrativo.

Mas não escolhi esse tipo de ficção barata apenas por essas razões.

As estórias de crime e investigação, de vilões e heróis, possuíam uma moralidade dúbia, nunca às claras, nunca facilmente reconhecível. Não sabíamos se o investigador não era o criminoso, ou se a pobre dama indefesa não se viraria contra o herói, ou ainda se o monstro não se revelaria o paladino de uma justiça perfeita, por mais que ambígua. Tais contos, quase sempre de vingança, traziam ao mundo caótico uma reordenação aprazível, confortadora.

Neles, ao menos no fim, tínhamos uma ilusão de compensação, senão divina, humana. Por razões que desconhecia na época, uma parte de mim ansiava por isso: por um cosmos no qual a justiça era possível, por um universo no qual pudéssemos dormir à noite tendo a certeza de que, ao menos em algum momento, haveria punição aos culpados. Odiando a desigualdade e qualquer noção de divindade, construí tal mundo nas minhas histórias, e, nelas, os culpados nunca ficavam impunes. Em minhas fábulas folhetinescas, os heróis sempre venciam (2014, p. 247). 
A partir destes exemplos, compreendo a narrativa de Lição de Anatomia como um exercício criativo cujo resultado indica uma polifonia ficcional e narrativa. Se pensarmos em polifonia enquanto recurso musical, trata-se de perceber diferentes arranjos sonoros que, apesar de diversos, comunicam um todo harmônico. Na seara literária, o romance polifônico - constitutivo da narrativa moderna, ao menos segundo Mikhail Bakhtin (1981) - instaura uma visão múltipla na qual não haveria uma única explicação ou condição. Como no mundo, tais romances apresentariam ao leitor uma série de perspectivas ou pontos de vista, dando a este a oportunidade de escolher aquele ou aqueles que me melhor se harmonizam com suas próprias.

No caso de A Lição de Anatomia do Temível Dr. Louison, o que tentei empreender foi uma revisita a diferentes histórias e vozes, a variadas perspectivas literárias que formam nosso imaginário textual e nossa própria memória cultural. A partir da releitura feita das criações de Machado de Assis, Álvares de Azevedo, Raul Pompeia e Augusto Emílio Zaluar, entre outros autores constitutivos do nosso cânone, espero que a experiência de leitura do primeiro volume de Brasiliana Steampunk seja instigante e inquietante, fazendo leitores e leitoras, experientes ou não, descobrir outras formas de ver e ouvir nossa tradição ficcional.

\section{Conclusão: construtos caracterológicos \& desafios metodológicos}

Escrever sobre o próprio trabalho é uma prática desaconselhada na academia literária, sintoma da pretensa morte do autor e da pouca valia de suas opiniões. Felizmente, a ascensão da crítica genética como uma abordagem genuína para se compreender o processo criativo parece estar mudando esse cenário. A partir desta perspectiva, este ensaio - que tentei empreender com questionável neutralidade e desejada objetividade - possa constituir um crime menor, passível de ser perdoado, especialmente em redutos acadêmicos mais tradicionais. Por outro lado, a reflexão sobre a criatividade é uma tarefa comum e obrigatória a toda tarefa humana, revelando especialmente tratar-se de uma simples questão metodológica: como e por que fazemos o que fazemos?

No meu caso, a percepção da metodologia - seja na pesquisa acadêmica seja na criação literária - é buscada de forma frequente e prazerosa, podendo ter por resultado a resposta que constituiria um inegável tesouro no final do arcoíris: de onde vêm as ideias? Muitas das reflexões que apresentei aqui já eram de meu conhecimento, estando presentes antes mesmo antes de realizá-las no conto de 2009 ou no romance de 2014. Mas outras, confesso, foram descobertas, percebidas ou desveladas, à medida que avançava nesta reflexão, constituindo assim uma feliz aventura tanto quanto o é para mim a escrita de ficção.

Concluo esta reflexão sobre a criação das vozes narrativas de Brasiliana Steampunk registrando aqui uma percepção que me acompanha há algum tempo, percepção ou inquietação que supostamente acompanha todo escritor ou escritora em formação: "Como encontrar a própria voz, o próprio estilo, o próprio texto?" No meu caso, revisitar os clássicos nacionais e estudar as elaboradas narrativas dos mestres literários que me precederam têm me auxiliado a encontrar um modo específico de planejar e criar a minha ficção. Como um baú 
de histórias, as vozes literárias que nos precederam são constitutivas das nossas. Ainda mais: são elas que nos ensinam a compreender as nossas próprias narrativas, sejam as biográficas ou as ficcionais.

\section{Referências}

BAHTIN, M. Problemas da poética de Dostoiévski. Rio de Janeiro: Forense Universitária, 1981.

FONDANÈCHE, D. L'Uchronie comme moteur de I'histoire (im)possible: L'Appel du 17 juin d'André Costa. Cycnos (Université de Nice), v. 22, n. 2. 2006, p. 1-9.

GIRARDOT, J.; MÉRESTE, F. Le Steampunk: une machine littéraire à recycler le passé. Cycnos (Université de Nice), v. 22, n. 1. 2006, p.1-11.

GUEIROS JR, N. O direito autoral no show business. Rio de Janeiro: Gryphos, 2005.

JETER, K. W. Morlock Night. Oxford: Angry Robot, 2011.

MATANGRANO, B. A. O olhar contemporâneo na releitura do moderno: A lição de anatomia do temível Dr. Louison. Estudos de Literatura Brasileira Contemporânea [Digital], n. 48, p. 247-280, 2016.

NEWMAN, K. Anno Dracula. Tradução de Susana Alexandria. São Paulo: Aleph, 2009.
PEGORARO, É. Os steampunks e a cultura da mídia: apropriações de uma proposta retrofuturista no cenário brasileiro. Revista Mediaciones Sociales (Universidad Complutense), v. II, p. 72-94, 2012.

PEGORARO, É. Retrofuturismo e visualidade steampunk no Brasil. Revista Latinoamericana de Ciencias de la Comunicación (ALAIC), v. 11, p. 88-96, 2014.

PEGORARO, É. Steampunk: as transgressões temporais negociadas de uma cultura retrofuturista. Cadernos de Comunicação (UFSM), v. 16, p. 389400, 2012.

ROBB, B. J. Steampunk: An illustrated history of fantastical ficcion, fancivul film and other victorian visions. Voyageur Press, 2012.

TAVARES, E. A lição de anatomia do temível Dr. Louison. Rio de Janeiro: Casa da Palavra, 2014.

TAVARES, E.; MATANGRANO, B. A. A humanização do monstro no seriado televisivo Penny Dreadful. Revista Abusões, v. 1, n. 1, p.181-219, 2016.

VANDERMEER, J.; BOSKOVICH, D. The Steampunk - User's manual. New York: Abrams Image, 2014. VANDERMEER, J.; CHAMBERS, S. J. The Steampunk Bible. New York: Abrams Image, 2011.

Recebido: 15 de julho de 2017. Aceite: 19 de julho de 2017. 